\title{
Effects of freeze-drying conditions on aerogel properties
}

\author{
Carolina Simón-Herrero ${ }^{1}$, Silvia Caminero-Huertas ${ }^{1}$, Amaya Romero ${ }^{1}$, \\ José L. Valverde ${ }^{1}$, and Luz Sánchez-Silva ${ }^{1, *}$ \\ ${ }^{1}$ Department of Chemical Engineering, University of Castilla La Mancha, Av. Camilo Jose Cela 12, 13071 Ciudad Real, Spain
}

Received: 18 April 2016

Accepted: 17 June 2016

Published online:

28 June 2016

(C) Springer Science+Business

Media New York 2016

\begin{abstract}
Carbon nanofiber-reinforced polymer aerogels have been successfully synthesized by means of a freeze-drying process. The influence of the different operation conditions on both the process efficiency and the aerogel physical properties has been evaluated. Morphology, porosity and conductivity of the resulting carbon nanofiber-reinforced polymer aerogels were investigated. Their density and porosity increased when the freezing time decreased. However, the porosity of the carbon nanofiber-reinforced polymer aerogels increased and when both the vacuum pressure and the freeze-drying temperature increased, respectively. No clear effect of the operating conditions on the thermal conductivity of the aerogels synthesized was detected, ranging from 0.037 to $0.069 \mathrm{~W} / \mathrm{m} \mathrm{K}$. The low values of thermal conductivity obtained suggest that these materials could be used for building insulation purposes. In addition, the addition of carbon nanofibers allowed to increase the mechanical resistance of the final product to be used as building insulation materials to reduce the energy consumption.
\end{abstract}

\section{Introduction}

Energy conservation is an important issue in order to get a sustainable development. An appreciable part of the total energy consumption of the world belongs to the building industry. Currently, materials such as aerogels and vacuum insulated panels are being used and investigated. Aerogels have porous structure, low density and very low conductivity compared to traditional materials [1, 2]. These properties allow to provide a sufficient insulation with a thin profile [3]. Some products are already available at the market, although their use is still constrained due to their high product cost. Aerogels are also very light materials. They consist of a gel in which the liquid compound has been replaced for a gas yielding a product of great porosity, low bulk density and high surface area. Freeze-drying and supercritical extraction of the solvent from the gel are among the most common processes to produce intact dried gel structures.

Organic aerogels have a structure based on organic polymers synthesized by multifunctional organic monomers polymerization, yielding a product that

Address correspondence to E-mail: marialuz.sanchez@uclm.es 
presents better thermal insulation properties than silica aerogels at ambient conditions [4]. In addition, they are less crumbly and brittle than inorganic aerogels.

The incorporation of carbonaceous nanomaterials, such as carbon nanofibers (CNFs) into the organic aerogels structure, is required to improve the mechanical properties of the aerogel. CNFs have useful thermal properties such as low thermal expansion coefficient and high thermal conductivity, which make them excellent candidates to develop multifunctional composites [5-7]. Furthermore, CNFs have remarkable electronic, physical and mechanical properties [8-11]. Thus, the incorporation of carbon nanomaterials into aerogel structures should lead to an enhancement of their thermal and electrical conductivity, by both decreasing the thermal expansion coefficient and increasing the strength of the aerogels network [12]. In addition, carbon nanofiber aerogels exhibit excellent fire resistance when they are exposed to the flame of the alcohol burner [13]. Polyvinyl alcohol aerogels based on carbon nanofiber (CNF aerogels) by means of the freeze-drying process have successfully synthesized in previous works $[14,15]$. The influence of the CNF content in the polymer aerogel and the use of different solvents on the physical, morphological and mechanical properties of the final aerogel composites were evaluated. However, no study of the influence of the operating conditions on the physicochemical properties of the resulting materials was made. It was also demonstrated the economic feasibility of the manufacturing process of aerogels proposed and that no toxic pollutants were released at temperatures below $180{ }^{\circ} \mathrm{C}$.

In this work, polymer aerogel composites reinforced with carbonaceous nanomaterials (CNFs) were synthesized by means of the freeze-drying method. Then, the influence of the freeze-drying operation conditions on the physical and morphological properties of the final aerogel composites was evaluated.

\section{Materials and methods}

\section{Materials}

Polyvinyl alcohol (10-98, Mw $61000 \mathrm{~g} / \mathrm{mol})$ of analytical grade was supplied by Fluka Chemical Co. Ltd. Water was purified by distillation followed by deionization using ion exchange resins. CNFs were obtained according to the procedure described by Jimenez et al. [16] and used as the reinforced material.

\section{Experimental process}

\section{Preparation of the carbon nanofiber-reinforced polymer aerogels}

Aerogel was prepared following a sol-gel method that allows to control the composition, homogeneity, microstructure, particle size, porosity, surface area and dispersion of the final products during their synthesis from molecular precursors [17]. There are several consecutive steps in the sol-gel method: mixing, gelation, aging, drying and sintering. Drying is an important step in the synthesis of the aerogels. Freeze-drying is often recognized as the best method for solvent removal to obtain dried products with the highest quality [18]. The process comprises three steps: freezing, primary drying and secondary drying.

\section{Freezing}

The freezing step is the most critical one in the whole freeze-drying process. It should avoid having interstices with concentrate liquid to get that all the drying is carried out by sublimation. Generally, the freezing temperatures are between -50 and $-85{ }^{\circ} \mathrm{C}$.

Freezing method used during the freeze-drying affects the structure of the ice formed, the water vapor during primary drying and the quality of the final dried product. Moreover, it influences on ice crystal morphology and size distribution.

An extreme crystal size can affect cellular membranes irreversibly and consequently to the final product texture. It is advisable working with high freezing rates, in spite of restricting the internal diffusion of water vapor. As a counterpart, the product drying is more uniform and the pore size distribution is more homogeneous.

Freezing rate controls the size of ice crystals and, therefore, the porosity of the dry layer, which could have an impact on drying time [19]. In general, the lower the freezing rate, the higher the size of the ice particles and the lower the number of them and the specific surface are. In addition, the compressive modulus increases and the layer thickness decreases for decreasing freezing temperature [20]. 


\section{Primary drying}

The primary drying step is based on the solid solvent sublimation. In this step, about $95 \%$ of the water present in the material is sublimated and the pressure is reduced to very low levels, whereas the temperature in the shelves is raised to facilitate solvent sublimation. It is the longest step of the freeze-drying process [21].

\section{Secondary drying}

The aim of secondary drying step is the elimination of unfrozen water molecules since the ice was removed in the primary drying phase. In this step, the temperature of the shelves is raised to values higher than those needed in the primary drying one in order to facilitate both the removal of residual solvent [21] and the vacuum pressure is decreased [22]. At the end of the operation, the final residual water content in the product should be very low, ranging from 1 to $4 \%$.

The method used for the preparation of carbon nanofiber-reinforced polymer aerogels has been reported elsewhere [15]. A solution of polymer (polyvinyl alcohol) in deionized water (1745.6 $\mathrm{mg}$ of PVA in $35 \mathrm{~mL}$ of water) was prepared under vigorous stirring until its complete dissolution $\left(82^{\circ} \mathrm{C}\right)$; $4.4 \mathrm{mg}$ of CNFs was dispersed in water using an ultrasonic bath ( $1 \mathrm{~h}$ at room temperature). After both solutions were cooled down to ambient temperature, they were mixed under vigorous stirring for $1 \mathrm{~min}$ to obtain the final product. The CNF suspension in the aqueous polymer solution was poured into the shelf of the freeze-drying equipment. Carbon nanofiberreinforced polymer aerogels were prepared by freezing of the wet gel in a laboratory freeze dryer (LyoQuest -85) at $-80{ }^{\circ} \mathrm{C}$. In a subsequent step, sample was dried by varying both the vacuum pressure and the freeze-drying temperature in order to optimize the variables of the process. The operation conditions used in the preparation of the different aerogels here prepared are listed in Table 1, and a schematic illustration of the synthesis is shown in Fig. 1. Notations for all samples are also given in Table 1. For example, ATC1 is an aerogel synthesized as follows: freezing time, $4.5 \mathrm{~h}$; vacuum pressure, $0.1 \mathrm{mbar}$; and freeze-drying temperature, $25^{\circ} \mathrm{C}$. Table 1 shows the operating conditions of the different experiments carried out.

\section{Characterization}

Thermal conductivity of the carbon nanofiber-reinforced polymer aerogels was measured with a thermal analyzer KD2 Pro using a single-needle (TR-1) sensor. The density of the aerogels was determined by using the scale (AG (Z) 100C-AG (Z) 50C); $200 \mathrm{~mL}$ of osmotized water and a sample of $2 \mathrm{~cm}$ of diameter were necessary to measure the density. Thus, the density value was obtained as described by Eq. 1:

$\rho=\frac{m_{1}}{m_{1}-m_{2}} * \rho_{\mathrm{L}}$

where $m_{1}$ is the weight in air; $m_{2}$ is the weight in water; and $\rho_{\mathrm{L}}$ is the liquid density.

The porosity was calculated according to Eq. 2:

$\varepsilon=\frac{V_{p}-V_{s}}{V_{p}}$

where $V_{p}$ is the volume of the carbon nanofiber-reinforced polymer aerogel samples and $V_{s}$ is the volume of the pure PVA polymer.

Morphology, shape and pores size in the aerogels were evaluated by scanning electron microscopy (Phenom Pro). This equipment had an analyzer of energy-dispersive X-ray spectroscopy (EDS) to determine the average composition of the aerogels. Prior to SEM measurements, the surface of the samples was coated with Au to improve the resolution of the micrographs. Thermal transitions of samples were analyzed by modulated differential scanning calorimetry (MDSC) using a DSC Q100 from TA Instruments by varying the temperature in the range from room temperature to $200{ }^{\circ} \mathrm{C}$ with a heating rate of $3{ }^{\circ} \mathrm{C} / \mathrm{min}$ under a nitrogen atmosphere. Pores size and distribution were computed by using a Mercury Porosimetry (Quantachrome Poremaster).

\section{Results and discussion}

The aim of this research was the preparation of carbon nanofiber-reinforced polymer aerogels to be used as insulating materials for building applications. In a previous work [15], the mechanical properties of these novel materials were analyzed by means of dynamic mechanical analysis (DMA). The values of storage modulus $\left(E^{\prime}\right)$ and loss modulus $\left(E^{\prime \prime}\right)$ of the aerogels were higher than those of the pure PVA. Thus, the addition of carbonaceous nanomaterials into polymeric matrix increased the mechanical 
Table 1 Operating conditions of the freeze-drying process

\begin{tabular}{lllll}
\hline & Samples & Freezing time $(\mathrm{h})$ & Vacuum pressure $(\mathrm{mbar})$ & Freeze-drying temperature $\left({ }^{\circ} \mathrm{C}\right)$ \\
\hline Set 1 & ATC1 & 4.5 & 0.1 & 25 \\
& ATC2 & 6 & 0.1 & 25 \\
& ATC3 & 8 & 0.1 & 25 \\
& ATC4 & 10 & 0.1 & 25 \\
Set 2 & AP1 & 6 & 0.01 & 25 \\
& AP2 & 6 & 0.025 & 25 \\
& AP3 & 6 & 0.05 & 25 \\
& AP4 & 6 & 0.06 & 25 \\
& AP5 & 6 & 0.08 & 25 \\
& AP6 & 6 & 0.1 & 25 \\
& AP7 & 6 & 0.5 & 25 \\
Set 3 & AT1 & 6 & 0.08 & 25 \\
& AT2 & 6 & 0.08 & 30 \\
& AT3 & 6 & 0.08 & 35 \\
& AT4 & 6 & 0.08 & 42 \\
& AT5 & 6 & 0.08 & 50 \\
\hline
\end{tabular}

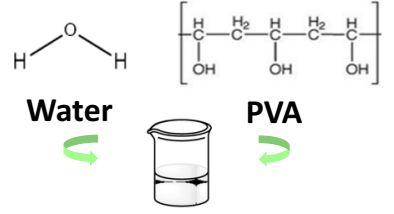

\section{Ultrasonic Bath (1h)}
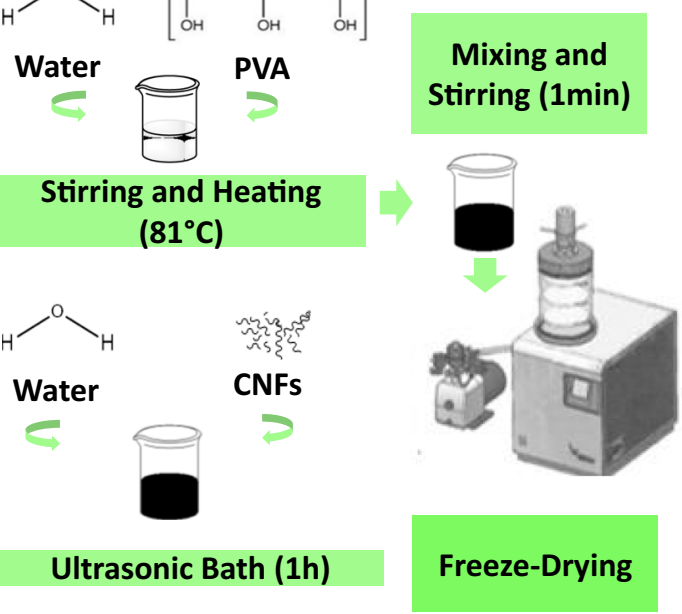

Figure 1 Scheme of synthesis of carbon nanofiber-reinforced polymer aerogels.

resistance. However, the influence of the operation conditions study of the freezing-drying process on the morphological and physical properties of aerogels has not been evaluated yet.

\section{The effect of the freezing time}

The freezing step can affect the structure of the ice formed, the water vapor flow during primary drying and the quality of the final dried product [23]. Consequently, it should dictate ice crystal morphology and size distribution [24]. According to previous studies, polyvinyl alcohol (PVA) was selected as the structural binder to improve the structure of the carbon nanofiber-reinforced polymer aerogels $[14,25]$. The effect of the freezing step on the carbon nanofiber-reinforced polymer aerogel synthesis was studied by varying the freezing time from 4.5 to $10 \mathrm{~h}$ (set 1, Table 1). Note that aerogels synthesized after $10 \mathrm{~h}$ of freezing were covered with a layer of frost that contaminated the final product.

Values of density of the carbon nanofiber-reinforced polymer aerogels obtained using different freezing times were in the range 94-110.9 $\mathrm{g} / \mathrm{L}$, which is in good agreement with those reported elsewhere $[26,27]$. Furthermore, as shown in Fig. 2, the higher the freezing time, the lower the density was.

According to the obtained results, density values of carbon nanofiber-reinforced polymer aerogels synthesized using the freeze-drying technique were lower than those reported for silica aerogel produced by the sol-gel method ( $80-200 \mathrm{~g} / \mathrm{L})$ [28]. Thus, the aerogels synthesized in this work could be used as ultralightweight materials for several industrial applications.

As above mentioned, the freezing rate controls the ice crystals size and, therefore, the porosity of the dry layer, which could have an impact over the drying time [18, 19]. Generally speaking, the lower the freezing rate, the higher the ice particles size and the lower both their number and the specific surface 
were. In addition, the compressive modulus increased and the layer thickness decreased with decreasing freezing temperatures [20]. Contrarily to

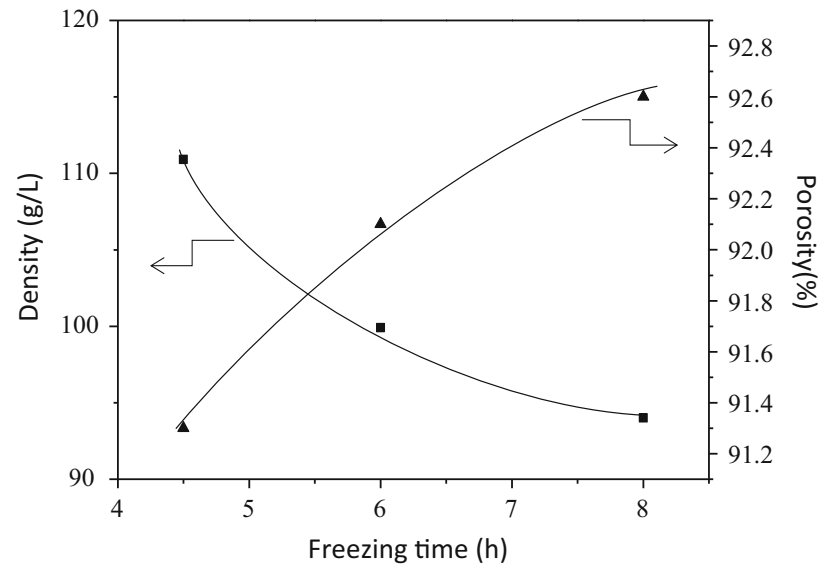

Figure 2 Densities and porosities of carbon nanofiber-reinforced polymer aerogels prepared from different freezing times. the results reported by Ratti [18], the density of the carbon nanofiber-reinforced polymer aerogels increased when the freezing time decreased. In addition, the lower the freezing time (what means that the freezing rate was increased), the lower the pores diameter and the higher the amount of pores amount and surface area were. Consequently, the porosity of the resulting materials should increase. However, the average porosity value did not increase, which was attributed to the different sizes of the pores present in each sample, which was in turn confirmed by means of scanning electron microscope (SEM) micrographs (Fig. 3). When the freezing time decreased (what means that the freezing rate increased), the size of the observed pores decreased, whereas their number rose up. Despite of this fact, the porosity did not increase because small pores occupied less volume than the big ones. The sample synthesized showed a great amount of small pore
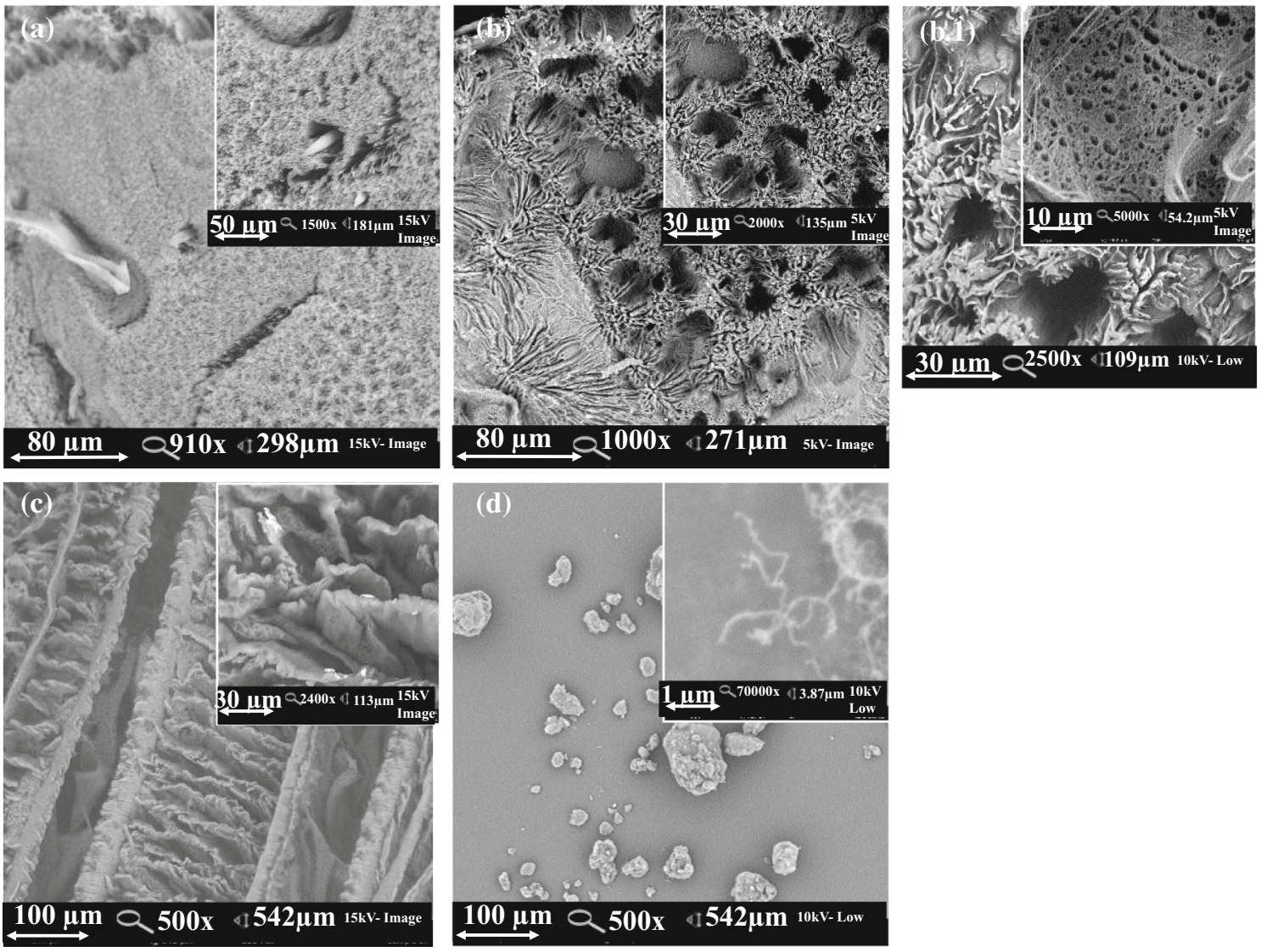

Figure 3 SEM micrographs of samples: a sample synthesised using $4.5 \mathrm{~h}$ of freezing time (ATC1); $\mathbf{b}$ sample synthesised using a freezing time of 6 h (ATC2), b.1 higher magnification of sample synthesised using 6 h; and c sample synthesised a freezing time of 8 h (ATC3) and d CNFs. 
size (Fig. 3a). Sample synthesized with a freezing time of $6 \mathrm{~h}$ presented bigger pores than sample ATC1 (Fig. 3b). Figure 3c shows micrographs of the sample synthesized with a freezing time of 8 . This sample shows the biggest pores at all, which were interconnected by means of channels. In addition, the magnification of the SEM image shows the fibrous structure of the carbonaceous nanomaterials (Fig. 3d), which were located into the polymeric
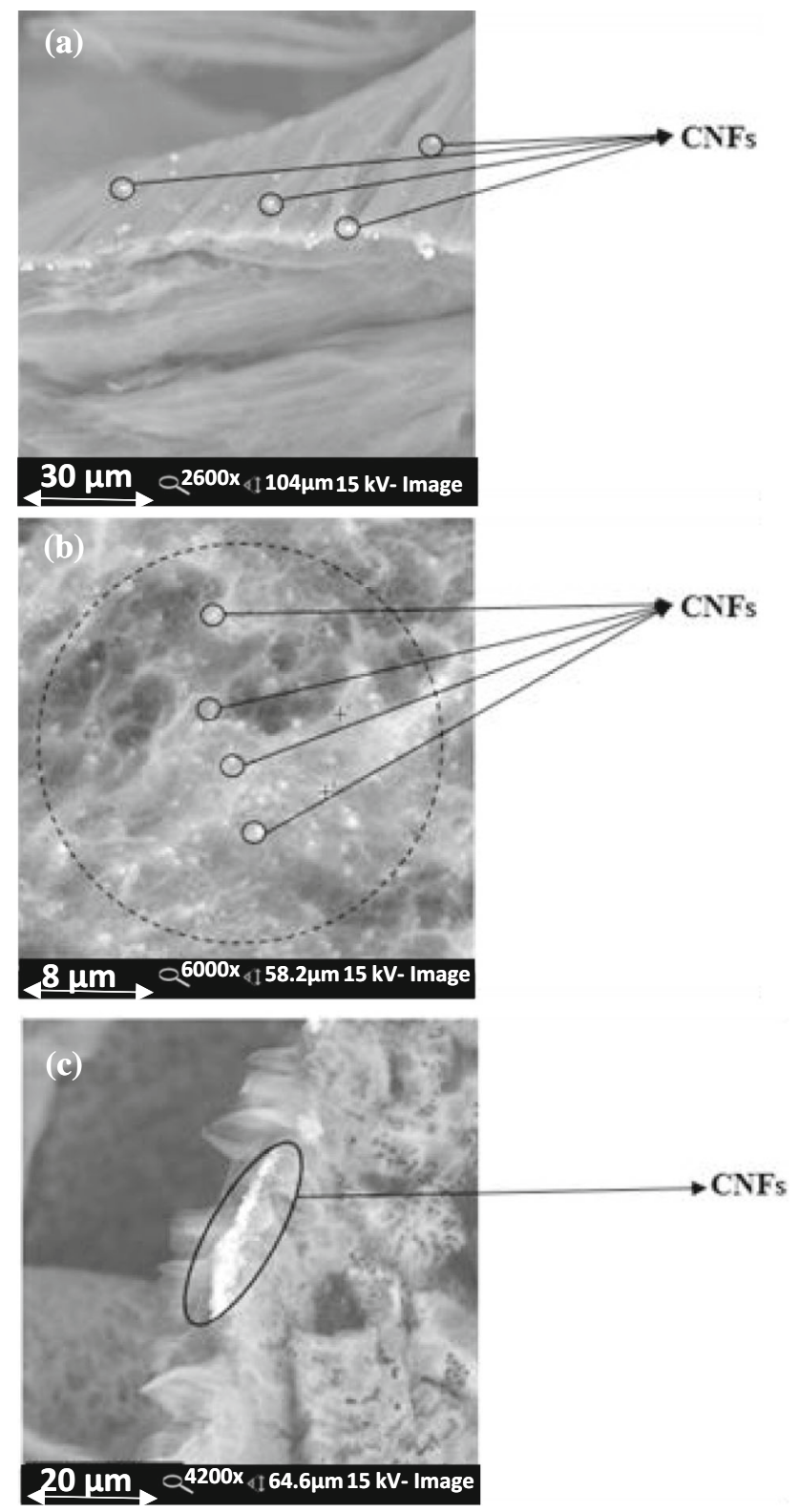

Figure 4 SEM micrographs using backscattering electron detector (BSED) of samples: a sample synthesised using a freezing time of $4.5 \mathrm{~h}$ (ATC1); $\mathbf{b}$ sample synthesised using a freezing time of $6 \mathrm{~h}$ (ATC2); and c sample synthesised using a freezing time of $8 \mathrm{~h}$ (ATC3). matrix by backscattering electron detector (BSED) (Fig. 4). This technique detects areas with different values of average atomic number by varying the signal intensity. Carbon nanofibers are identified in by the most illuminated areas in the images. As observed, the worse dispersion of CNFs in the polymeric matrix was associated with higher freezing times. Sample synthesized with a freezing time of $8 \mathrm{~h}$ showed CNFs agglomerations, which reduced the reinforcement capacity.

On the other hand, thermal conductivity of the different aerogels synthesized was not practically affected by the variation of freezing time since they were in the range $0.051-0.058 \mathrm{~W} / \mathrm{m} \mathrm{K}$. Anyway, these values were low enough to consider these aerogels as potential insulators in building construction [28]. To corroborate the observed results, a porosimetry analysis of sample ATC2 was carried out. A bimodal pore size distribution at around 65 and $0.25 \mu \mathrm{m}$ (macropores), respectively, was detected (Fig. 5). Small pores were abundant, but they occupied less empty volume than the big ones. The porosimetry measurements agreed well to those previously evaluated by SEM. Elemental analyses by energy-dispersive X-ray spectroscopy (EDS) were performed in order to determine the average composition of the carbon nanofiber-reinforced polymer aerogels. EDS analyses showed the presence of oxygen $(65.7 \mathrm{wt} \%)$ and carbon $(34.3 \mathrm{wt} \%)$.

On the basis of the obtained results, aerogel synthesized with a freezing time of $6 \mathrm{~h}$ was selected as the reference for further studies since it showed better values of porosity than sample prepared with a freezing time of $4.5 \mathrm{~h}$ and led to a lesser production costs than that with a freezing time of $8 \mathrm{~h}$, which in turn presented a higher agglomeration of CNFs that negatively affected the mechanical properties of the resulting aerogels.

\section{The effect of the vacuum pressure}

The effect of the vacuum pressure on the synthesis of carbon nanofiber-reinforced polymer aerogels was studied by varying this parameter from 0.01 to 0.5 mbar (set 2, Table 1) [29] and keeping constant the sublimation rate. Values of density and conductivity of aerogels synthesized using a vacuum pressure of 0.5 mbar were not considered for comparison purposes since the time needed to complete their manufacture was very long. Correspondingly, 


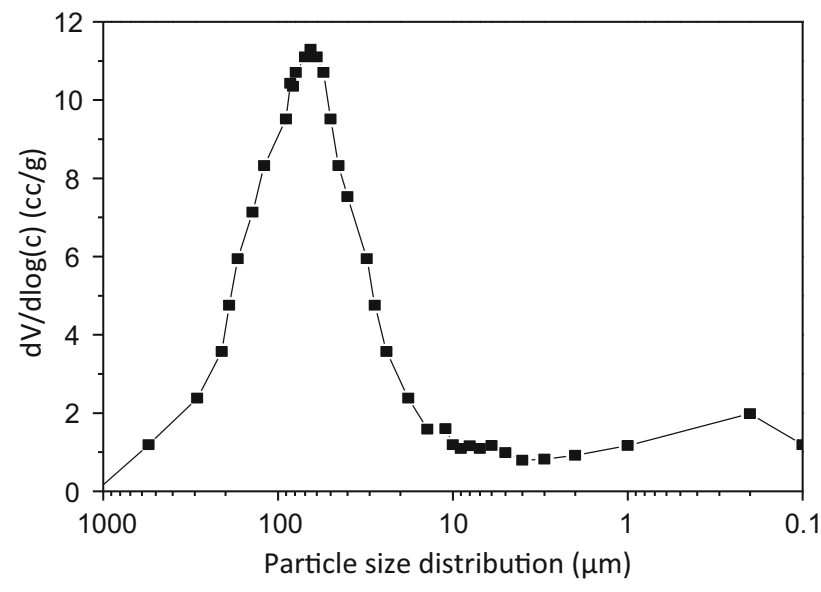

Figure 5 Pore size distribution for sample synthesized at a freezing time of $6 \mathrm{~h}$ (ATC2).

values of these properties of aerogels prepared using a vacuum pressure of 0.01 mbar were not also considered because this pressure was the minimum value that the equipment was able to get and its measurement did not result to be stable and reproducible. In addition, it was finally observed that samples manufactured using a vacuum pressure of 0.1 mbar were not completely dried at the moderate drying times used in the rest of the experiments performed in this section. This way, the vacuum pressure range from 0.03 to 0.08 mbar was selected in order to ensure that the freeze-drying stage was completed on time.

Figure 6 shows that the vacuum pressure range studied (0.03-0.08 mbar) did not have an influence on the density of the resulting carbon nanofiber-reinforced polymer aerogels, which ranged from 89.7 to $103.6 \mathrm{~g} / \mathrm{L}$. According to Ratti [18], the porosity of carbon nanofiber-reinforced polymer aerogels increased when the vacuum pressure increased due to the large heterogeneity of the heat transfer mechanism associated with the low vacuum level $[18,30]$. Moreover, when the pressure increased, the heat transmission by convection also did, leading to a more efficient process and yielding aerogels with best characteristics. This fact was confirmed, as shown in Fig. 7, by means of mercury porosimetry analysis of samples synthesized using a vacuum pressure of 0.05 and 0.08 mbar (samples AP3 and AP5, respectively). A bimodal pore diameter distribution was observed in both cases. Small pores were less abundant than the big ones. Furthermore, the sample synthesized using 0.05 mbar showed a lower intrusion volume than that obtained

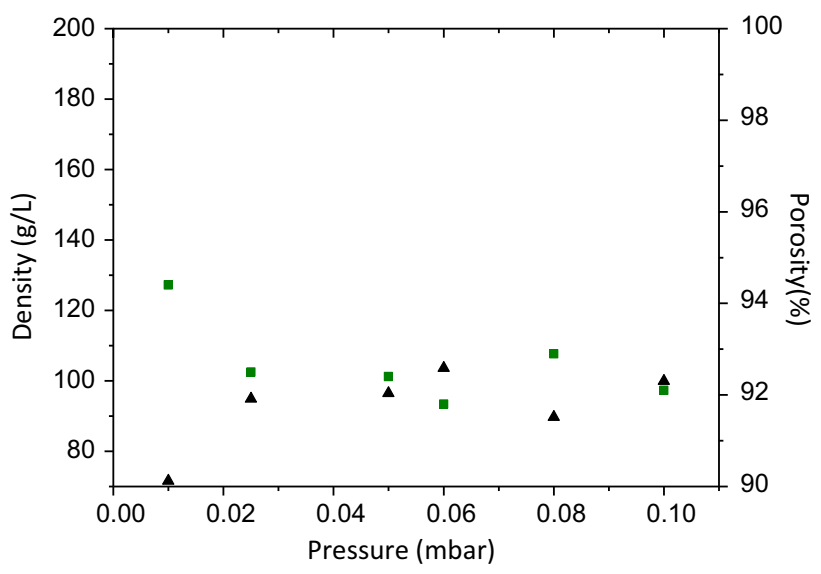

Figure 6 Densities and porosities of carbon nanofiber-reinforced polymer aerogels prepared using different vacuum pressures.

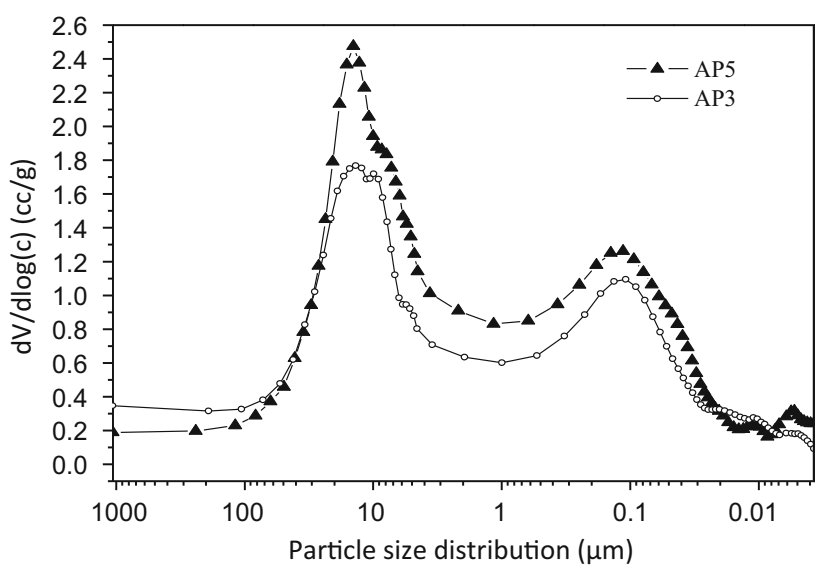

Figure 7 Pore size distribution for samples AP3 (synthesized using a vacuum pressure of 0.05 mbar) and AP5 (synthesized using a vacuum pressure of 0.08 mbar).

using a vacuum pressure of $0.08 \mathrm{mbar}(4.3138 \mathrm{cc} / \mathrm{g}$ for sample AP5 and $3.6434 \mathrm{cc} / \mathrm{g}$ for sample AP3).

On the other hand, thermal conductivity values in all cases were kept practically constant within the range from 0.045 to $0.060 \mathrm{~W} / \mathrm{m} \mathrm{K}$.

On the basis of the obtained results, aerogel synthesized using a vacuum pressure of 0.08 mbar was selected as the reference for further studies. This sample presented an adequate porosity and low values of both thermal conductivity and density. It could be also used as potential insulator for building construction purposes [28].

\section{The effect of the freeze-drying temperature}

Freeze-drying temperature is an important parameter to be studied, which affects the quality of the final 


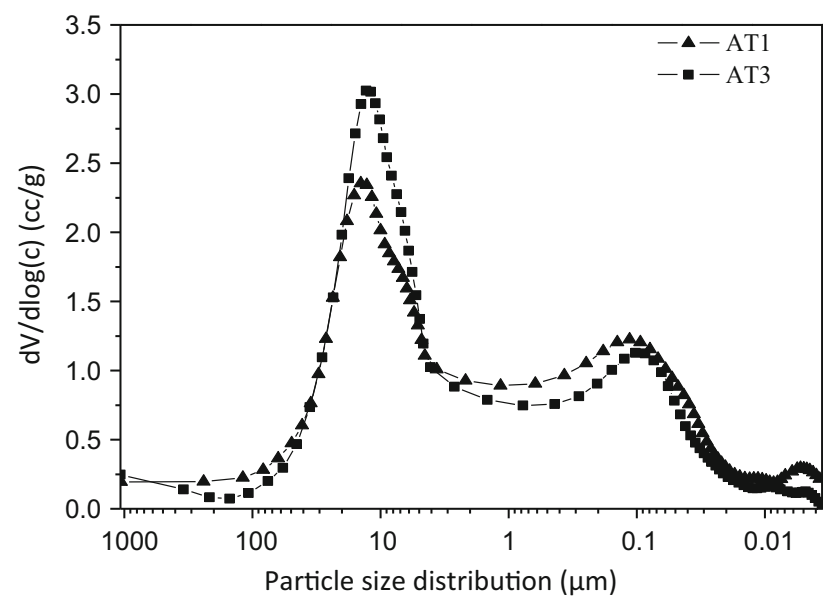

Figure 8 Pore size distributions for samples AT1 and AT3.

products. An increase in the freezing-drying temperature leads to a reduction in energy consumption during the whole process, but it can accelerate material deterioration [18]. The effect of this parameter on the synthesis of carbon nanofiber-reinforced polymer aerogels was evaluated by varying its value from 25 to $50{ }^{\circ} \mathrm{C}$ (set 3, Table 1). The values of density and porosity of the aerogel manufactured at $50{ }^{\circ} \mathrm{C}$ did not follow any logical trend if compared to those of the aerogels produced at lower temperatures. In fact, the values of its density and apparent mechanical resistance were much lower than expected. According to Fig. 8, a bimodal pore diameter distribution was observed for all the samples, being small pores less abundant than the large ones. Density values for all the carbon nanofiber-reinforced polymer aerogels ranged from 79.6 to 89.7 g/L (Fig. 9), which corresponds to ultralight materials. The higher

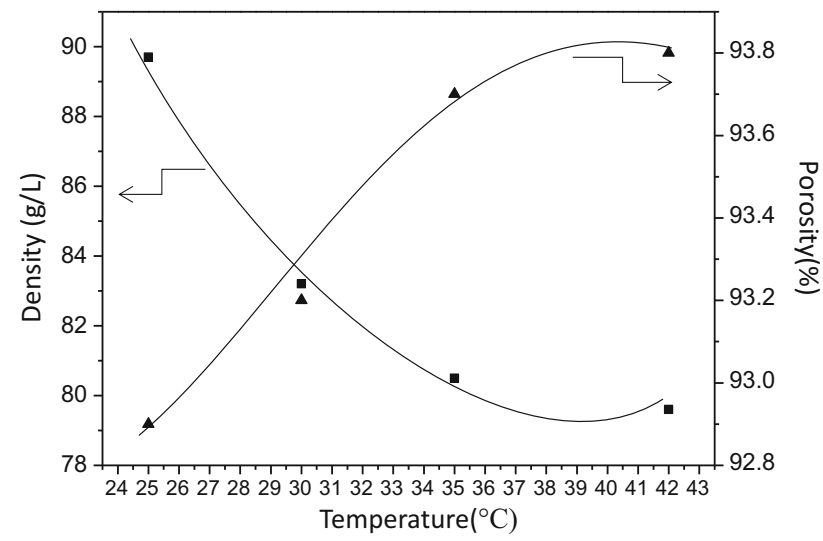

Figure 9 Densities and porosities of carbon nanofiber-reinforced polymer aerogels prepared using different freezing-drying temperatures. the freeze-drying temperature, the higher the value of porosity was. On the other hand, thermal conductivity values associated ranged in turn from 0.037 to $0.047 \mathrm{~W} / \mathrm{m} \mathrm{K}$. Among all the materials prepared in this section that manufactured at $35{ }^{\circ} \mathrm{C}$ presented the best combination of properties for being used as an ultralight insulator in building construction.

\section{Conclusions}

Carbon nanofiber-reinforced polymer aerogels were successfully obtained by means of a sol gel method. These novel materials presented excellent thermal properties and textural characteristics to be applied as insulating materials in building construction. The higher the freezing time, vacuum pressure and freezing temperature, the higher the porosity of the final aerogels was. In addition, the values of thermal conductivity were similar for all the aerogels here prepared. The best physical properties were attained for the nanomaterial-reinforced polymer aerogel prepared according to the following operating conditions: $6 \mathrm{~h}$ of freezing time, 0.08 of vacuum pressure and $35{ }^{\circ} \mathrm{C}$ of freeze-drying temperature.

\section{Acknowledgements}

The present work was performed within the frame of the NANOLEAP project. This project has received funding from the European Union's Horizon 2020 research and innovation program under Grant Agreement No. 646397.

\section{References}

[1] Pääkkö M, Vapaavuori J, Silvennoinen R, Kosonen H, Ankerfors M, Lindström T, Berglund LA, Ikkala O (2008) Long and entangled native cellulose I nanofibers allow flexible aerogels and hierarchically porous templates for functionalities. Soft Matter 4:2492-2499

[2] Olsson RT, Azizi Samir MAS, Salazar-Alvarez G, Belova L, Ström V, Berglund LA, Ikkala O, Nogués J, Gedde UW (2010) Making flexible magnetic aerogels and stiff magnetic nanopaper using cellulose nanofibrils as templates. Nat Nanotechnol 5:584-588

[3] Qi H, Mäder E, Liu J (2013) Electrically conductive aerogels composed of cellulose and carbon nanotubes. J Mater Chem A 1:9714-9720 
[4] Pekala RW, Alviso CT, Lu X, Gross J, Fricke J (1995) New organic aerogels based upon a phenolic-furfural reaction. J Non-Cryst Solids 188:34-40

[5] Yang S, Taha-Tijerina J, Serrato-Diaz V, Hernandez K, Lozano K (2007) Dynamic mechanical and thermal analysis of aligned vapor grown carbon nanofiber reinforced polyethylene. Compos B-Eng 38:228-235

[6] Al-Saleh MH, Sundararaj U (2009) A review of vapor grown carbon nanofiber/polymer conductive composites. Carbon $47: 2-22$

[7] Poveda RL, Achar S, Gupta N (2014) Viscoelastic properties of carbon nanofiber reinforced multiscale syntactic foam. Compos B-Eng 58:208-216

[8] Zhang L, Aboagye A, Kelkar A, Lai C, Fong H (2014) A review: carbon nanofibers from electro spun polyacrylonitrile and their applications. J Mater Sci 49:463-480

[9] Ghaleb ZA, Mariatti M, Ariff ZM (2014) Properties of graphene nanopowder and multi-walled carbon nanotubefilled epoxy thin-film nanocomposites for electronic applications: the effect of sonication time and filler loading. Compos A-Appl 58:77-83

[10] Klemm D, Kramer F, Moritz S, Lindström T, Ankerfors M, Gray D, Dorris A (2011) Nanocelluloses: a new family of nature-based materials. Angew Chem Int Ed 50:5438-5466

[11] Moon RJ, Martini A, Nairn J, Simonsen J, Youngblood J (2011) Cellulose nanomaterials review: structure, properties and nanocomposites. Chem Soc Rev 40:3941-3994

[12] Neubauer E, Kitzmantel M, Hulman M, Angerer P (2010) Potential and challenges of metal-matrix-composites reinforced with carbon nanofibers and carbon nanotubes. Compos Sci Technol 70:2228-2236

[13] Wu Z, Li C, Liang H, Chen J, Yu S (2013) Ultralight, flexible, and fire-resistant carbon nanofiber aerogels from bacterial cellulose. Angew Chem Int Ed 52:2925-2929

[14] Sánchez-Silva L, Víctor-Román S, Romero A, Gracia I, Valverde JL (2014) Tailor-made aerogels based on carbon nanofibers by freeze-drying. Sci Adv Mater 6:665-673

[15] Víctor-Román S, Simón-Herrero C, Romero A, Gracia I, Valverde JL, Sánchez-Silva L (2015) CNF-reinforced polymer aerogels: influence of the synthesis variables and economic evaluation. Chem Eng J 262:691-701

[16] Jiménez V, Nieto-Márquez A, Díaz JA, Romero R, Sánchez P, Valverde JL, Romero A (2009) Pilot plant scale study of the influence of the operating conditions in the production of carbon nanofibers. Ind Eng Chem Res 48:8407-8417

[17] Luis M, Carballo S, Hugo M, Galindo V (2001) Estudios de los Procesos sol-gel para la Obtención de un Aglutinante Apropiado para el Paletizado de Alúmina. Ing Investig 48:57-63
[18] Ratti C (2012) Freeze-drying process design. In: Ahmed J, ShafiurRahman M (eds) Handbook of food process design. Wiley-Blackwell, Oxford, pp 621-647

[19] Hammami C, René F (1997) Determination of freezedrying process variables for strawberries. J Food Eng $32: 133-154$

[20] Wang Y, Gawryla MD, Schiraldi DA (2013) Effects of freezing conditions on the morphology and mechanical properties of clay and polymer/clay aerogels. J Appl Polym Sci 129:1637-1641

[21] Kramer T, Kremer DM, Pikal MJ, Petre WJ, Shalaev EY, Gatlin LA (2009) A procedure to optimize scale-up for the primary drying phase of lyophilization. J Pharm Sci 98:307-318

[22] Zhai S, Su H, Taylor R, Slater NKH (2005) Pure ice sublimation within vials in a laboratory lyophiliser; comparison of theory with experiment. Chem Eng Sci 60:1167-1176

[23] Patapoff TW, Overcashier DE (2002) The importance of freezing on lyophilization cycle development. Biopharm 3:16-21

[24] Searles JA, Carpenter JF, Randolph TW (2001) the ice nucleation temperature determines the primary drying rate of lyophilization for samples frozen on a temperature-controlled shelf. J Pharm Sci 90:860-871

[25] Skaltsas T, Avgouropoulos G, Tasis D (2011) Impact of the fabrication method on the physicochemical properties of carbon nanotube-based aerogels. Microporous Mesoporous Mater 143:451-457

[26] Chen HB, Liu B, Huang W, Wang JS, Zeng G, Wu WH, Schiraldi DA (2014) Fabrication and properties of irradiation-cross-linked poly (vinyl alcohol)/clay aerogel composites. ACS Appl Mater Interfaces 61:16227-16236

[27] Lewicki JP, Worsley MA, Albo RLF, Finnie JA, Ashmore M, Mason HE, Baumann TF, Maxwell RS (2014) The effects of highly structured low density carbon nanotube networks on the thermal degradation behaviour of polysiloxanes. Polym Degrad Stab 102:25-32

[28] Koebel M, Rigacci A, Achard P (2012) Aerogel-based thermal superinsulation: an overview. J Sol-Gel Sci Technol 63:315-339

[29] Tsinontides SC, Rajniak P, Pham D, Hunke WA, Placek J, Reynolds SD (2004) Freeze drying principles and practice for successful scale-up to manufacturing. Int $\mathrm{J}$ Pharm 280:1-16

[30] Tang XC, Pikal MJ (2004) Design of freeze-drying processes for pharmaceuticals: practical advice. Pharm Res 21:191-200 